\title{
Direction Selectivity Mediated by Adaptation in the 0wl's Inferior Colliculus
}

\author{
Yunyan Wang and José Luis Peña \\ Dominick P. Purpura Department of Neuroscience, Albert Einstein College of Medicine, Bronx, New York 10461
}

\begin{abstract}
Motion direction is a crucial cue for predicting future states in natural scenes. In the auditory system, the mechanisms that confer direction selectivity to neurons are not well understood. Neither is it known whether sound motion is encoded independently of stationary sound location. Here we investigated these questions in neurons of the owl's external nucleus of the inferior colliculus, where auditory space is represented in a map. Using a high-density speaker array, we show that the preferred direction and the degree of direction selectivity can be predicted by response adaptation to sounds moving over asymmetric spatial receptive fields. At the population level, we found that preference for sounds moving toward frontal space increased with eccentricity in spatial tuning. This distribution was consistent with larger receptive-field asymmetry in neurons tuned to more peripheral auditory space. A model of suppression based on spatiotemporal summation predicted the observations. Thus, response adaptation and receptive-field shape can explain direction selectivity to acoustic motion and an orderly distribution of preferred direction.
\end{abstract}

Key words: sound localization; direction selectivity; adaptation; map of space

\section{Introduction}

Direction selectivity (DS) in the auditory system has been studied in the contexts of frequency modulation (FM) and motion in space. Encoding FM is important for vocal communication and echolocation (Suga and Schlegel, 1973; Mendelson and Cynader, 1985; Rauschecker, 1997; Razak and Fuzessery, 2006). FM is analogous to movement in visual space, as motion occurs over the tonotopic and retinotopic axes of the auditory and visual receptors, respectively. There is mounting evidence that DS for FM sweeps can be explained by asymmetric excitation and inhibition across the tonotopic axis (Casseday et al., 1994; Zhang et al., 2003; Ye et al., 2010; Kuo and $\mathrm{Wu}, 2012$ ). These mechanisms are consistent with findings in vision where asymmetric circuit structure confers DS in the retina (Briggman et al., 2011; Wei et al., 2011; Vaney et al., 2012).

DS for sound motion is crucial for tracking auditory objects in space. Neural sensitivity to auditory motion direction has been reported in many species (Sovijärvi and Hyvärinen, 1974; Rauschecker and Harris, 1989; Reale and Brugge, 1990; Wagner and Takahashi, 1990; Ahissar et al., 1992; Stumpf et al., 1992; Spitzer and Semple, 1993; Wilson and O'Neill, 1998; Ingham et al., 2001; Malone et al., 2002). Processing spatial motion may require different mechanisms compared with vision, as auditory space is

\footnotetext{
Received July 9, 2013; revised Oct. 24, 2013; accepted Oct. 30, 2013.

Author contributions:Y.W. and J.L.P. designed research;Y.W. performed research; Y.W. analyzed data; Y.W. and J.L.P. wrote the paper.

This work was supported by National Institutes of Health Grants F31 DC012000 to Y.W., and R01 DC007690 to J.L.P., and by a grant from the US-Israel Binational Science Foundation to J.L.P. We thank Michael Beckert, Fanny Cazettes, Gervasio Batista, and Brian Fischer for feedback and comments on the paper.

The authors declare no competing financial interests.

Correspondence should be addressed to Yunyan Wang, Rose F. Kennedy Center 529, Albert Einstein College of Medicine, 1300 Morris Park Avenue, Bronx, NY 10461. E-mail: yunyan.wang@phd.einstein.yu.edu DOI:10.1523/JNEUROSCI.2920-13.2013

Copyright $\odot 2013$ the authors $\quad 0270-6474 / 13 / 3319167-09 \$ 15.00 / 0$
}

computed, rather than mapped on the receptor's surface. Adaptation has been proposed to underlie DS (Ingham et al., 2001; Malone et al., 2002; Ingham and McAlpine, 2004; Shestopalova et al., 2012), because it provides a mechanism for activation history to affect subsequent response.

Although adaptation is widely reported in the auditory system (Harris and Dallos, 1979; Ingham and McAlpine, 2004; Ulanovsky et al., 2004; Gutfreund and Knudsen, 2006; Ayala and Malmierca, 2013; Singheiser et al., 2012), few studies have directly linked the time course of adaptation with selectivity for sound motion (Ingham et al., 2001; Malone et al., 2002; Ingham and McAlpine, 2004). Simulations based on the summation of suppression (Reid et al., 1991; Jagadeesh et al., 1993; Tolhurst and Heeger, 1997) could explain motion sensitivity in vision, suggesting temporal integration may be important for generating DS. Models of inferior colliculus (IC) neurons showed that adaptation could give rise to sensitivity to dynamic binaural cues observed during sound motion (Cai et al., 1998b).

We studied the relationship between the time course of adaptation and DS in a population of space-specific neurons of the owl's midbrain (Knudsen and Konishi, 1978), using a dense hemispheric speaker array. We found that in fact adaptation could predict DS in single cells based on the properties of the neurons' spatial receptive field (SRF). In addition, we found that systematic changes in receptive field shape across the population could account for a topographic representation of DS overlapping the map of auditory space.

\section{Materials and Methods}

Surgery

Adult barn owls of both sexes ( 3 males, 1 female) were implanted with stainless steel head plates and a reference post, as described previously (Steinberg and Peña, 2011; Wang et al., 2012). A dental acrylic well was built around the craniotomy above external nucleus of the IC (ICx) for repeated sessions in each animal. 
Owls were food-deprived $12 \mathrm{~h}$ before recording. At each recording session, anesthesia consisting of intramuscular injections of ketamine hydrochloride (20 mg/kg; Ketaset) and xylazine ( $4 \mathrm{mg} / \mathrm{kg}$; Anased) was administered with prophylactic antibiotics (ampicillin; $20 \mathrm{mg} / \mathrm{kg}$, i.m.) and lactated Ringer's solution ( $10 \mathrm{ml}$, s.c.). The depth of anesthesia was monitored by pedal reflex. Additional injections were given to maintain anesthesia during the experiment. Body temperature was maintained throughout the session with a heating pad.

At the end of each session, the craniotomy was sealed with a clear quick-curing silicone compound (Quick-Pro, Warner Tech-Care). An intramuscular injection of carprofen $(3 \mathrm{mg} / \mathrm{kg}$, Rimadyl) was given to relieve inflammation and pain. All owls were able to fly the day following recording. Owls were allowed to recuperate in their home cages for 7-10 $\mathrm{d}$ before the next session. These procedures comply with guidelines set forth by the National Institutes of Health and by the Albert Einstein College of Medicine's Institute of Animal Studies.

\section{Extracellular recording}

Tucker Davis Technologies (TDT) System 3 and custom programs written in Matlab (MathWorks) were used to present all acoustic stimuli and record neural data. All experiments were performed in a double-walled sound-attenuating chamber (Industrial Acoustics) lined with echoabsorbing acoustical foam (Sonex).

ICx was located stereotaxically and by the characteristic responses to interaural time difference (ITD) and interaural level difference (ILD; Moiseff and Konishi, 1981; Takahashi et al., 1984; Peña and Konishi, 2001). Single and multiunit responses were recorded using $1 \mathrm{M} \Omega$ tungsten electrodes (AM Systems) advanced in steps of $10 \mu \mathrm{m}$ to the level of optic tectum, then at steps of 2-4 $\mathrm{m}$ during search in ICx (Motion Controller, model ESP300, Newport).

\section{Acoustic stimuli}

Dichotic stimulation. We used custom-made earphones each consisting of a speaker (Knowles, model 1914) and a microphone (Knowles, model 1319) housed in a cylindrical metal earpiece that fits in the owl's ear canal. Microphones inside the earphones were calibrated before experiments using a Fostex speaker (FE87E) and a reference Brüel and Kjær microphone (model 4190; Steinberg and Peña, 2011; Wang et al., 2012).

Auditory stimuli delivered through the earphones consisted of five repetitions of $100 \mathrm{~ms}$ duration broadband signals $(0.5-10 \mathrm{kHz})$ or tones, with a $5 \mathrm{~ms}$ rise-fall time at $10-20 \mathrm{~dB}$ above threshold. For each ICX neuron, we first measured the ITD, ILD, frequency tuning, and rateintensity response using dichotic stimulation. ITD varied from $\pm 300 \mu \mathrm{s}$, and ILD from $\pm 40 \mathrm{~dB}$, where negative values represent sounds leading and louder on the left ear, respectively. Frequency ranged from $500 \mathrm{~Hz}$ to $10 \mathrm{kHz}$ and sound level varied from $0 \mathrm{~dB}$ SPL to $70 \mathrm{~dB}$ SPL. Five trials of each test were collected. Stimuli within the tested ranges were randomized during data collection.

Earphones were removed for testing in the free-field, after which earphones were replaced and recalibrated before searching for the next unit with dichotic stimulation.

Stationary receptive field mapping. Free-field spatial tuning of each neuron was measured using a custom-made hemispherical array of 144 speakers (Sennheiser, 3P127A) constructed inside the sound-attenuating chamber (Pérez and Peña, 2006; Wang et al., 2012). The speaker array ranged $\pm 100^{\circ}$ in azimuth and $\pm 80^{\circ}$ in elevation. The angular separation between the speakers varied from $10^{\circ}$ to $30^{\circ}$. The highest density of speakers was located in frontal space, at the center of the array $\left( \pm 40^{\circ}\right.$ around origin) and on the horizontal and vertical axes passing through the origin $\left( \pm 100^{\circ}\right.$ azimuth, $\pm 80^{\circ}$ elevation). Each speaker in the array was calibrated using a Brüel and Kjær microphone (model 4190). The calibration apparatus was mounted on a custom-built pan-tilt robot positioned at the center of the array. The robot oriented the microphone toward the speaker being calibrated, with fine adjustments assisted by a laser-mounted webcam. Each speaker's transfer function was then measured using a Golay code technique (Zhou et al., 1992), after which an output voltage rms versus stimulus-intensity (dB SPL) curve was computed and stored (Wang et al., 2012). All acoustic stimuli in free field were presented within the dynamic range of the rate-intensity curve for each unit (typically $30-45 \mathrm{~dB}$ SPL).

A linear subset of 21 speakers located at $-100^{\circ}$ to $100^{\circ}$ in azimuth at $0^{\circ}$ elevation was used to map the SRF in azimuth. Spatial separation between speakers in this subset was $10^{\circ}$. Broadband $(0.5-10 \mathrm{kHz})$ sound bursts $25 \mathrm{~ms}$ in duration were presented at random locations within the 21 speaker subset. Up and down-ramps for each burst were $5 \mathrm{~ms}$ and the interstimulus interval was $300 \mathrm{~ms}$. Forty-five to 50 trials were tested for each speaker location. Each unit's preferred direction was designated as the midpoint in the spatial tuning curve main peak at half-maximum. After a unit's spatial tuning was determined, the owl was rotated so the center of the unit's SRF was aligned to $0^{\circ}$ azimuth. Stationary SRF mapping was repeated with the owl in the new orientation and subsequent free-field tests were performed in this condition.

\section{Simulated acoustic motion in free field}

Moving sound stimuli were presented with the same 21-speaker array used for stationary SRF mapping. Motion was initiated at $-100^{\circ}$ or $100^{\circ}$. Broadband $25 \mathrm{~ms}$ sound bursts were presented in sequence across the array. Onset and offset ramps of adjacent speakers overlapped in time to create a perceptually smooth motion. The duration of each moving stimulus was $425 \mathrm{~ms}$ for a $200^{\circ}$ displacement, or $470 \%$ s. Previous studies have used speeds ranging from 125 to $1200 \%$ in birds and mammals (Rauschecker and Harris, 1989; Wagner and Takahashi, 1990, 1992; Ingham et al., 2001). Motion from left-to-right (LR) or right-to-left (RL) was randomized over 250 trials with $1 \mathrm{~s}$ of silence between trials. Clicks (1 ms duration) were also used for moving stimuli. Motion velocity was controlled by changing the interclick interval (ICI). ICIs of 25 and $250 \mathrm{~ms}$ were used to test the effect of motion speed.

Adaptation test. Each trial consisted of a pair of $1 \mathrm{~ms}$ clicks presented at a single speaker location corresponding to the center of the receptive field for each neuron. ICIs were randomized between 50 and $500 \mathrm{~ms}$ over 800 trials. The interval between pairs of clicks was $800 \mathrm{~ms}$.

\section{Data analysis}

Isolation of single units was validated offline by spike-sorting using Wave_Clus (Quiroga et al., 2004). Stationary azimuthal SRFs were computed by averaging the firing rate in response to each speaker for $100 \mathrm{~ms}$ after the onset of stimulus. For SRFs in the moving condition, each moving stimulus was treated as one trial. peristimulus time histograms (PSTHs) were calculated with $5 \mathrm{~ms}$ bins. The direction selectivity index (DSI) is described in Equation 1, where $\mathrm{FR}_{L R}$ is the firing rate at the center of the SRF for the LR motion direction and $\mathrm{FR}_{R L}$ is the firing rate for the $R L$ direction. We defined the center as the five speakers that covered the main peak of the SRF $\left( \pm 20^{\circ}\right)$. Positive and negative values of DSI distinguish preference for the LR and RL directions, respectively.

$$
\mathrm{DSI}=\frac{\mathrm{FR}_{L R}-\mathrm{FR}_{R L}}{\mathrm{FR}_{L R}+\mathrm{FR}_{R L}}
$$

Side peak asymmetry (SPA) was calculated in the same way as DSI using the sum within $40^{\circ}$ to $80^{\circ}$ at either side of the main peak.

Adaptation in pairs of clicks was quantified by comparing the responses to the first (C1) and second (C2) click. Responses to clicks usually lasted between 5 and $30 \mathrm{~ms}$. Spikes were counted for $30 \mathrm{~ms}$ after taking into account the response latency for each cell. Firing rates for the first and second clicks were grouped across the ICI range in $35 \mathrm{~ms}$ bins. Each bin contained at least 50 trials. Normality of all datasets was assessed using the Lilliefors test.

\section{Model of spatiotemporal summation}

Linear spatiotemporal summation was used to model response adaptation during motion and to predict DS. Excitation elicited by the $n^{\text {th }}$ speaker in the moving-sound sequence was scaled by the amplitude of the response in the stationary receptive field $\left(\mathrm{SRF}_{n}\right)$. Response adaptation, represented as suppression $\left(\mathrm{S}_{n}\right)$, recovered over time $(t)$ for the duration of the sound at each position. Decay of adaptation was modeled as an exponential function (Sen et al., 1996; Varela et al., 1997; Oxenham, 2001) drawn from the data, using a least-square fit (Matlab) with $1 \mathrm{~ms}$ 
A
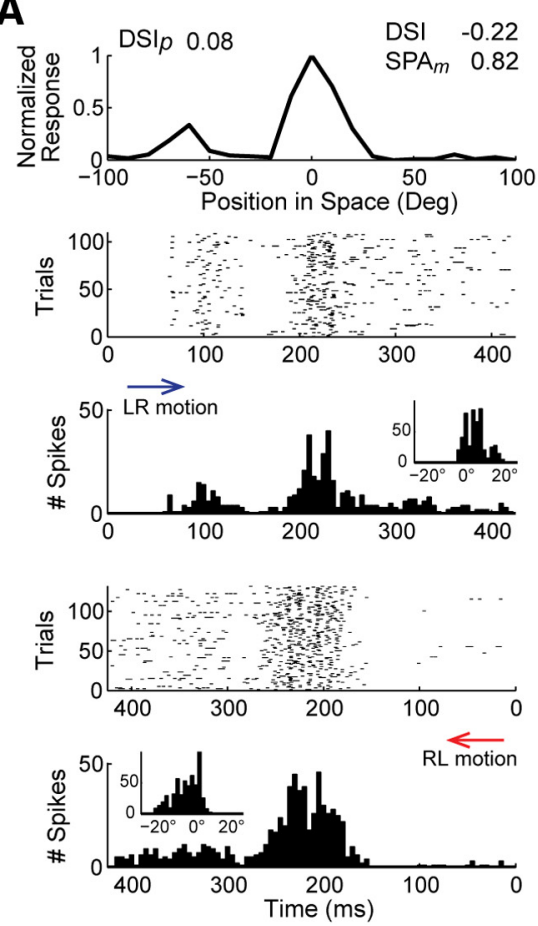

B
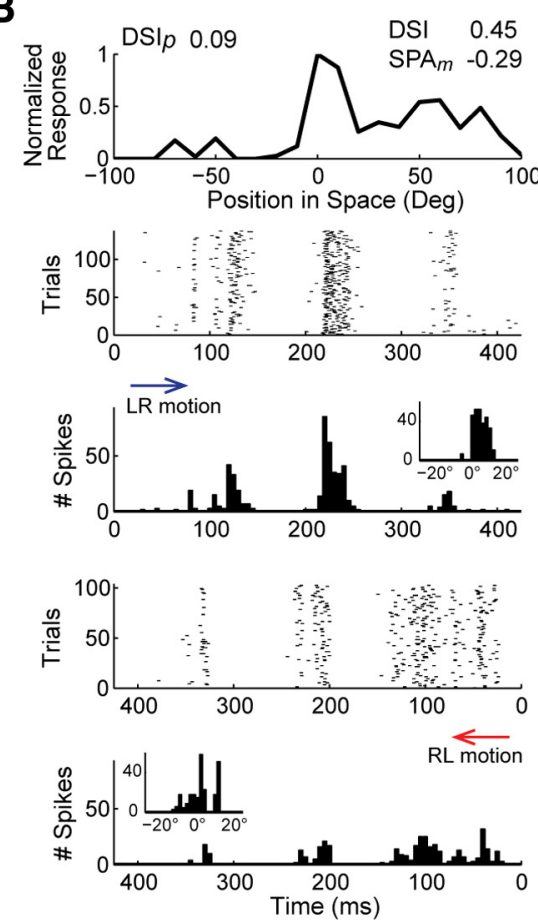

C
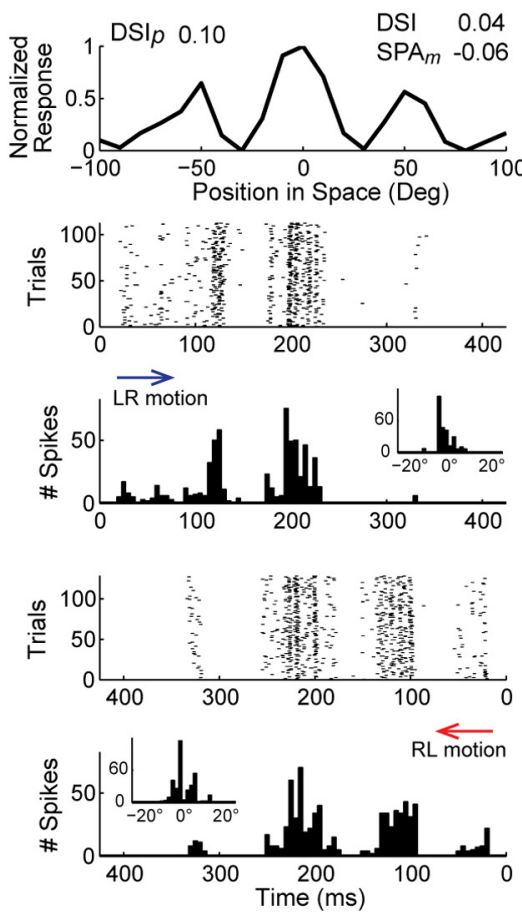

Figure 1. Receptive-field shape and direction-dependent responses. For each column, the top panel represents the stationary receptive field of an example neuron. The second and third panels represent raster and PSTH in the LR motion directions, whereas the fourth and fifth panels represent the same for the RL direction. Time axes of panels $2-5$ are aligned to corresponding positions in space relative to the top panel. Positive SPA $A_{m}$ indicates larger left side peak, whereas positive DSI indicates preference for the LR motion direction. Blue and red arrows indicate the onset position and direction of motion. Cells in $\boldsymbol{A}$ and $\boldsymbol{B}$ show attenuated responses at center when the larger side peak was stimulated before the center. In all three examples, attenuation of the side peak following center was strong in either motion direction. Insets show PSTHs to sounds moving over a subset speaker array $\left( \pm 20^{\circ}\right)$. Direction selectivity for stimulation of only the center is usually weaker and is indicated at the top-left corner of each column (DSIp).

sampling rate and time constant $(\tau)$ for each cell's adaptation curve (Sen et al., 1996; Varela et al., 1997). The starting value of adaptation at the $n^{\text {th }}$ speaker depended on suppression carried over from stimuli at previous locations $\left(\mathrm{S}_{n-1}\right.$; Eq. 2$)$ such that adaptation accumulates over multiple stimuli when they occurred in quick succession.

$$
\mathrm{S}_{n}(\mathrm{t})=\operatorname{SRF}_{n}\left(1-\mathrm{e}^{-\frac{\mathrm{t}}{\tau}}\right)-\mathrm{S}_{n-1}(\mathrm{t})
$$

Adaptation over the course of the moving stimulus in the LR or RL directions was estimated from the stationary SRF for each cell by summing suppression elicited by each speaker from $-100^{\circ}$ or $100^{\circ}$ end of the array.

To predict the SRF during motion $\left[\operatorname{SRF}_{\text {mov }}(t)\right]$, the stationary SRF $\left(\mathrm{SRF}_{\text {stat }}\right)$ was multiplied by the time-dependent suppression function, $S(t)$, in the LR or RL directions (Eq. 3).

$$
\operatorname{SRF}_{\text {mov }}(\mathrm{t})=\mathrm{SRF}_{\text {stat }} \mathrm{S}(\mathrm{t})
$$

Because suppression accumulated over time, responses elicited later in time were more strongly suppressed. DSI in the model was calculated in the same way as in the data. The response latency for each neuron was used to temporally align the observed and predicted SRFs.

\section{Results}

Data from 111 ICx single units were included in this study. ICx cells were narrowly tuned to elevation and azimuth and showed a wide range of sensitivity to motion.

\section{Receptive-field asymmetry predicts direction selectivity}

Azimuthal SRF in the stationary condition were recorded from $-100^{\circ}$ to $100^{\circ}$ with the region of maximal excitation aligned at the center of the array. The center peak was flanked by smaller side peaks of varying size, located $40^{\circ}-80^{\circ}$ to either side. In ICx, spatial tuning in azimuth arises from the selectivity to ITD
(Moiseff and Konishi, 1983). Rate-ITD curves in ICx exhibit a larger peak at the characteristic delay and smaller side-peaks as a result of the convergence of ITD channels across frequency (Takahashi and Konishi, 1986; Mori, 1997; Mazer, 1998).

The cells' responses differed between stationary and moving stimulus conditions. Figure 1 shows three examples of responses under stationary and moving conditions. Cells in Figure $1 A, B$ were sensitive to motion direction. Specifically, the cell in Figure $1 A$ preferred the RL direction, when the response at the center was preceded by the smaller side peak. Motion in the LR direction elicited a larger response before arriving at the center, which had a strong attenuating effect. The same was true for the example in Figure $1 B$, although in the opposite direction; the right side peak was larger and the LR direction was preferred by this cell. In Figure $1 C$, side peak sizes were similar and the cell was only weakly selective for motion direction at center. In all three examples, the response amplitude at side-peaks in the moving condition was similar to that in the stationary SRF when they preceded center during motion. However, responses at the side peaks were significantly attenuated when they followed response at the center. DS was also tested for moving stimuli in a subset of the speaker array corresponding to only the main peak of the SRF $\left( \pm 20^{\circ}\right)$, thus excluding side peaks. DS was weak when there was no stimulation at the side peaks, demonstrating their strong contribution to DS (Fig. 1, insets). The attenuating effects of the cell's firing on future responses indicated that the shape of the SRFs could significantly influence how neurons respond to moving sounds, in a manner consistent with adaptation.

The relationship between SRF asymmetry and DS was demonstrated for the entire dataset in Figure 2. In the LR motion direction, the left side peak preceded the center, whereas the right 
side peak preceded the center in the RL direction. The response at the center was proportional to the difference between the side peaks preceding the center in either motion direction, referred to as side peak asymmetry under the moving condition $\left(\mathrm{SPA}_{m}\right)$. This relationship is plotted in Figure $2 A$, which shows that when the left side peak was larger $\left(\mathrm{SPA}_{m}>0\right), \mathrm{RL}$ was the preferred motion direction $($ DSI $<0)$. The converse was true for cells with larger right side peaks, which showed a preference for LR motion direction (DSI >0). Asymmetry between left and right side peaks was also quantified for the stationary SRF, referred to as side peak asymmetry under stationary conditions $\left(\mathrm{SPA}_{s}\right)$, to disambiguate from the moving condition. DSI was also significantly correlated with $\mathrm{SPA}_{s}$ (Fig. $2 B$ ), further indicating that the response to side peaks was a robust predictor of DSI. The ratio of side peak response magnitude after and before stimulation at center was 0.23 (median, interquartile range 0.43 , Wilcoxon rank sum test $p<10^{-18}$ ) reflecting the attenuating effect of response at center on the subsequent side peak. The ratio between DSIs measured using the subset and full arrays was $0.35 \pm 0.05$ ( $n=24 ; t$ test, $p<$ $10^{-7}$ ), indicating DS was more robust when side peaks were stimulated. Thus, the activation history was closely correlated with DS.

\section{Topography of direction selectivity}

Across the population, ICx cells exhibited a wide range of DS and side peak asymmetry (Fig. 2). We thus looked into whether this variability could be explained by where neurons were located in the map of auditory space. In other words, we examined whether DS and SRF asymmetry were correlated with the neurons' spatial tuning, which itself is tied to the neurons' location in the map (Knudsen and Konishi, 1978). Seventy-two of 111 cells showed a larger ipsilateral side peak. There was a weak but significant correlation between side-peak asymmetry and tuning eccentricity such that more peripherally tuned cells showed larger side-peak asymmetry (Fig. 3A). Grouped analysis by spatial tuning at intervals of $10^{\circ}$ revealed a systematic reduction in contralateral side-peak height with increasing eccentricity in spatial tuning (Fig. 3B).

There was a weak but significant trend for laterally tuned neurons to show stronger preference for sounds moving toward the front, indicated by the higher number of neurons with negative DSIs (Fig. 3C). Although correlations between $\mathrm{SPA}_{s}$ and spatial tuning (Fig. $3 A$ ) and between DSI and spatial tuning (Fig. $3 C$ ) were low, they were nonetheless both statistically significant and consistent with one another. These observations suggest there is a topographic distribution of DS overlapped with the map of auditory space in ICx, where preference for sounds moving from the periphery to the front increases with tuning eccentricity (Fig.
B

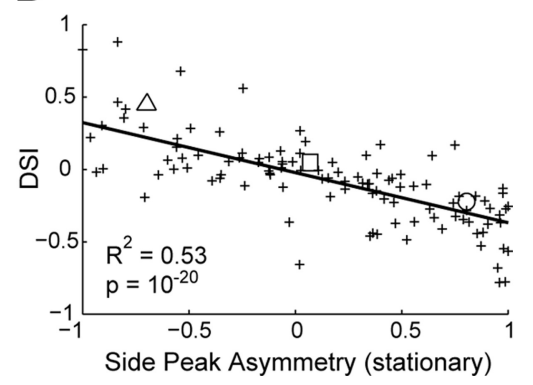

Figure 2. Side-peak asymmetry predicts direction selectivity. DSI was negatively correlated with side peak asymmetry in the espectively. Positive side-peak asymmetry indices indicate larger side peaks on the left side of the SRF's center. Symbols $\bigcirc, \Delta$, and

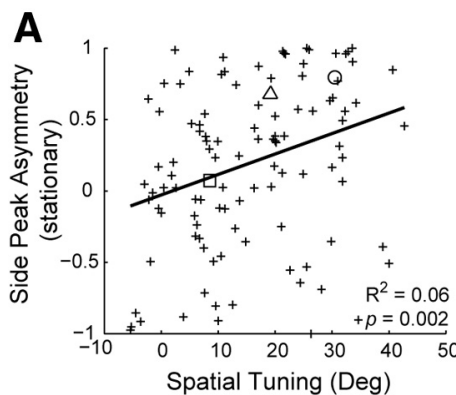

C

Figure 3. Side-peak asymmetry and direction selectivity across the neural population. $A$, Side-peak asymmetry in the stationary in the contralateral side-peak size with eccentricity. The centers of the SRFs for all groups were aligned at $0^{\circ}$ for comparison. SRFs of cells collected from the right hemisphere were flipped around $0^{\circ}$ so that ipsilateral space falls on the negative side of the $x$-axis. Ipsilateral and rection increases with tuning eccentricity, as indicated by negative DSIs for peripherally tuned cells. D, Schematic of DS topography in ICX. ty for moving sounds entering frontal space increases with spatial-tuning eccentricity. Dashed arrow indicates the preferred motion direction and the gray gradient indicates the degree of directional preference. Symbols $\bigcirc, \Delta$, and $\square$ in $A$ and $C$ indicate neurons shown in Figure $1 A-C$, respectively.

3D). The most lateral spatial tuning in the recorded sample was $45^{\circ}$, reflecting a known difficulty in accessing the most lateral areas of the ICx map (Knudsen and Konishi, 1978; Wagner et al., 2007). However, because there is an overrepresentation of frontal space, the sampled area covered most of the nucleus (Fig. 3D; Knudsen and Konishi, 1978).

\section{Adaptation as a mechanism for direction selectivity}

Because adaptation appeared as a plausible mechanism underlying DS, we used paired-click stimulation to test whether the temporal dynamics of response adaptation could explain DS in 44 ICx neurons. Figure $4 A$ shows an example response to a click (C2) presented at different delays after a preceding click (C1; Fitzpatrick et al., 1995; Brosch and Schreiner, 1997; Wehr and Zador, 2005; Gutfreund and Knudsen, 2006; Singheiser et al., 2012). The response suppression to 
A

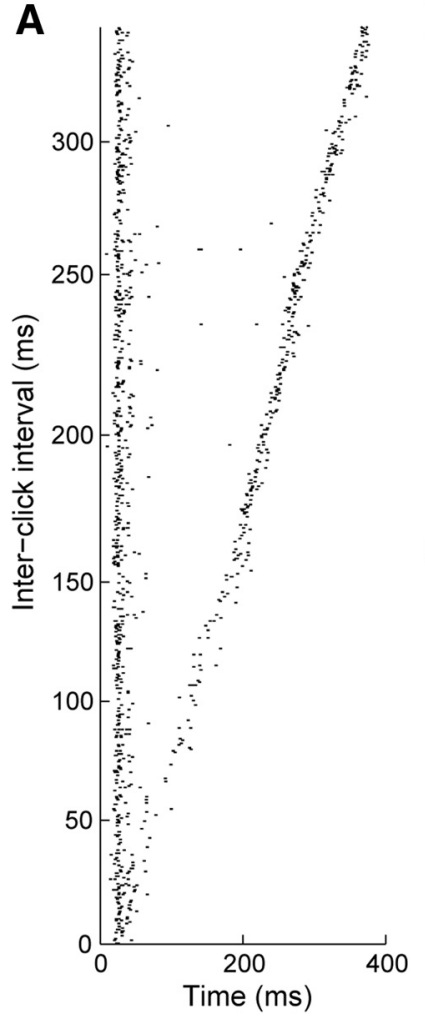

B

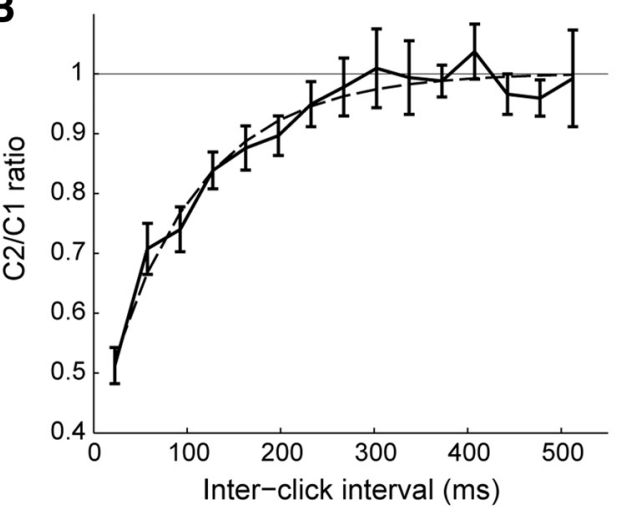

C

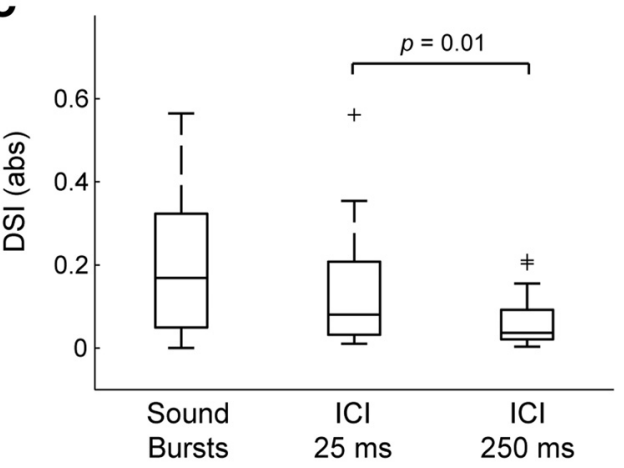

Figure 4. Correlation between adaptation and direction selectivity. $\boldsymbol{A}$, Example cell showing adaptation to paired-click stimulation. $\boldsymbol{B}$, Adaptation time course. The $\mathrm{C} / \mathrm{C} 1$ ratio approaches 1 (solid line) near $250 \mathrm{~ms}(n=44)$. Dashed line represents the exponential fit to the data ( $\tau=98 \mathrm{~ms}$ ). C, DSI for three motion conditions. Absolute values of direction selectivity indices are shown for motion stimulus consisting of $25 \mathrm{~ms}$ sound bursts click stimuli with short ( $25 \mathrm{~ms}$ ) and long ( $250 \mathrm{~ms}$ ) ICls. Long ICls elicited significantly smaller DSIs than moving stimuli with short ICls (Wilcoxon rank sum test). Boxplots represent the median, $25^{\text {th }}$, and $75^{\text {th }}$ quartiles and the range of data. Plus signs represent outliers.

C2 was strongest when ICIs were $<250 \mathrm{~ms}$. The averaged time course for adaptation could be described by an exponential function with a time constant $(\tau)$ of $98 \mathrm{~ms}$ (Fig. $4 B$ ). Double-exponential fits (Yin, 1994; Ulanovsky et al., 2004; Singheiser et al., 2012) to the averaged adaptation data were not distinguishable from single exponential functions. The two types of exponential functions yielded highly correlated predictions $\left(R^{2}=0.86\right)$. For simplicity, we used a single exponential function to describe the temporal properties of adaptation with one variable, $\tau$.

If adaptation underlies DS, then the response to motion speed should be explained by the time course of adaptation. We then measured DS using clicks spaced by short intervals $(25 \mathrm{~ms})$ when adaptation was strong and long intervals $(250 \mathrm{~ms})$ when adaptation was weak. Stimulation with clicks elicited weaker direction selectivity than with overlapping sound bursts (Fig. 4C). This can be explained by the effect of gaps between sounds (Wagner and Takahashi, 1992), which may allow for recovery from response suppression. Nevertheless, DS was stronger for stimuli with short ICIs. The effects of interclick interval on DS were consistent with the temporal properties of response adaptation, where suppression was strongest for ICIs $<250 \mathrm{~ms}$ (Fig. 4A).

\section{Temporal summation of suppression predicts direction selectivity}

We constructed a model of response adaptation such that suppression was summed during the motion trajectory. This model is based on short-term plasticity lasting several hundred milliseconds (Varela et al., 1997). We used a sample of 44 cells to test whether the model could predict the directionality from their decay time constant $\tau$. Because the moving sound could be decomposed into stationary sounds at each speaker in the array (Reid et al., 1991; Jagadeesh et al., 1993, 1997), the model treated the stimulus as a sequence of 21 (number of speakers) consecutive stimuli that are contiguous in space. Each sound that excited the cell triggered an amount of suppression proportional to the response at that location. The decay in suppression after the onset of sound was defined by $\tau$. Short intervals between stimuli resulted in accumulated suppression over time because there was not enough time for suppression to decay to zero (Fig. 5A). Figure $5 B$ shows the response to stationary stimuli of the same cell as Figure $1 A$, where the cumulative suppression for LR (blue arrow) and RL (red arrow) motion directions were modeled as time-dependent scaling factors or $\mathrm{S}(t)$ (see Materials and Methods). Motion starts at either end of the array where suppression elicited by each sound causes large downward deflections in the scaling factor (Fig. 5B, bottom). The magnitude of the suppression is proportional to the response magnitude in the stationary SRF ( SRF $_{\text {stat }}$; Fig. $5 B$, top). We scaled the $\mathrm{SRF}_{\text {stat }}$ by the time-dependent cumulative suppression $S(t)$ in each direction to estimate the SRF during motion $\left(\mathrm{SRF}_{\text {mov }}\right)$. This transformation of the $\mathrm{SRF}_{\text {stat }}$ gave a close prediction of $\mathrm{SRF}_{\text {mov }}$ for both LR and RL directions (Fig. 5C,D).

To test the effects of suppression decay time on DS, we compared the model's prediction using different time constants. The distribution of $\tau$ from adaptation is shown in Figure 6A. Each cell's individual adaptation $\tau$ generated predictions for direction selectivity index that matched the data well (Fig. 6B). When a short $\tau(25 \mathrm{~ms})$ was used to predict DS for all cells, the model underestimated DS (Fig. 6C), because fast-decaying response suppression did not accumulate over time. Large $\tau$ values produced good predictions of DSI (Fig. 6D). This lack of overestimation was likely due to the short interstimulus intervals (25 ms) relative to the decay time constants. Differences in suppression decay were more prominent among fast-decaying functions as demonstrated by the underestimation of DS with short $\tau$. Thus, linear spatiotemporal summation of adaptation was sufficient to produce the observed DS in ICx neurons.

\section{Discussion}

This study builds upon existing evidence to establish a link between response adaptation and the emergence of DS in the auditory system (Cai et al., 1998b; Malone et al., 2002; Ingham and McAlpine, 2004). A model based on spatiotemporal summation of response adaptation could predict each cell's DS using their individual adaptation time constant. On the population level, preference for sounds entering the front increased with eccentricity. This was consistent with increased SRF asymmetry for peripherally tuned cells. Our findings suggest that sensitivity to motion may be a general property for spatially tuned cells that adapt. 


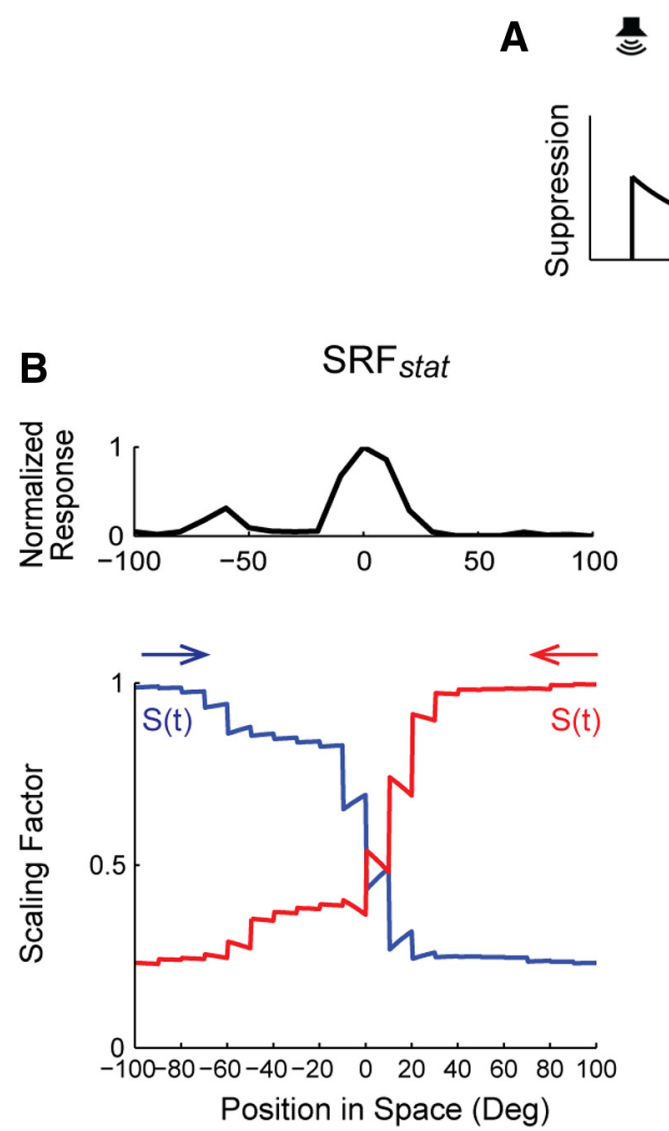

C

$\mathrm{SRF}_{\text {mov }}$
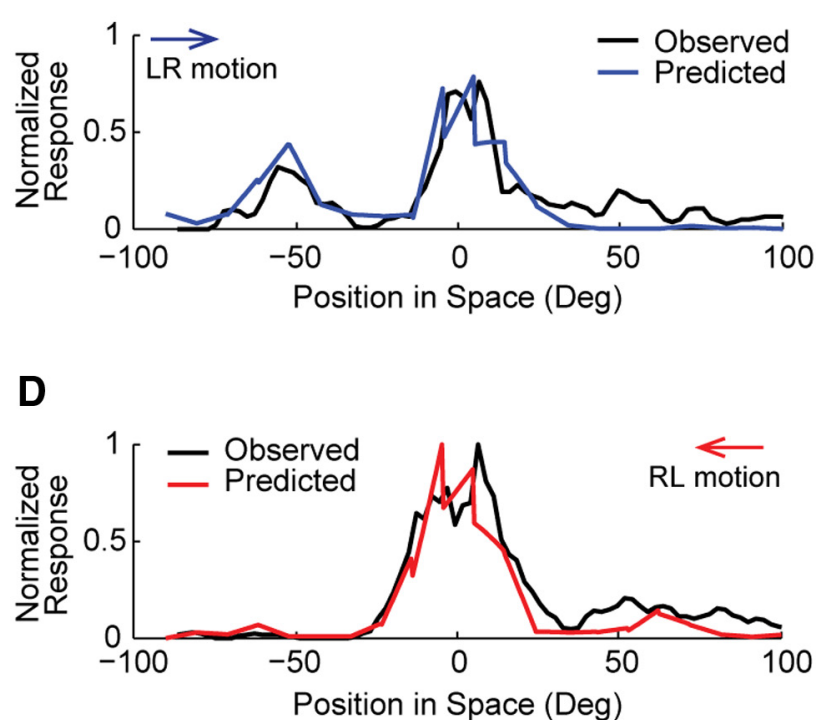

Figure 5. Spatiotemporal summation model. $\boldsymbol{A}$, Schematic for suppression accumulation. Response suppression elicited by excitation at each speaker location was modeled as an exponential decay function. When a second stimulus is presented before suppression decays to zero, adaptation accumulates over time. $\boldsymbol{B}$, Temporal suppression summation. Top, SRF of the neuron shown in Figure $1 A$ measured with stationary sounds ( $S R F_{\text {stat }}$. Bottom, Suppression over time, or $\mathrm{S}(\mathrm{t})$, was summed for the $L \mathrm{R}$ (blue arrow) and RL (red arrow) motion directions, starting at each end of the array. The amount of suppression is represented as a normalized scaling factor ( $0-1,1$ representing no suppression), weighted by the response magnitude at each position in the SRF. Suppression decays during the intervals between sounds. The scaling factor decreases more quickly in the $L R$ direction, from $-60^{\circ}$ to $0^{\circ}$, due to the larger side peak on the left. $x$-Axes for $\boldsymbol{B}$ (bottom), $\boldsymbol{C}$, and $\boldsymbol{D}$ represent spatial positions at corresponding times during motion stimulation. $\boldsymbol{C}, S R F$ s under the moving sound condition $\left(\mathrm{SRF}_{\text {mov }}\right)$ were predicted by multiplying the $S R F_{\text {stat }}\left(\boldsymbol{B}_{\text {, top }}\right)$ by either the blue (LR) or red (RL) time-dependent scaling functions ( $\boldsymbol{B}$, bottom). Curves were smoothed over $50 \mathrm{~ms}$. Observed and predicted SRFs were aligned by adjusting for the neuron's response latency. In all panels, LR and RL directions are indicated by blue and red colors, respectively. Arrows indicate motion directions.

\section{Comparisons with previous studies}

In this study, we show that each cell's DS depended on its SRF asymmetry, which in turn was correlated with the cell's tuning in space. Parameters, such as speaker density and angular distance, determine stimulation in the surround, thus affecting DS at the center. These parameters must be considered when interpreting past work on DS in the owl IC (Wagner and Takahashi, 1990, 1992).

The population trend for DS in ICx is in agreement with fMRI studies showing hemispheric preference for auditory motion in the contra-to-ipsilateral direction in humans (Getzmann, 2011). Our results are, however, in contrast with the preference for outward sounds reported by Wagner and von Campenhausen (2002). We explain this inconsistency by methodological differences between studies. The coarser array $\left(30^{\circ}\right.$ between speakers) used in the previous study may not be sufficient to map and stimulate regions of the SRF that surround the excitatory center. Further, DS trends reported in Wagner and von Campenhausen (2002) were derived from a pooled population of several midbrain nuclei and across all elevations whereas we restricted our analysis to only ICx cells responsive at $0^{\circ}$ elevation.

In the context of DS, the adaptation time course could determine the sensitive range of motion velocities. Using clicks, we showed that DS decreased for long interstimulus intervals over the same spatial displacement. This is in agreement with Wagner and Takahashi (1992), where DS was strong for motion velocities faster than $300 \%$ and weaker for slower velocities.

\section{Emergence of SRF asymmetry}

The correlation between motion selectivity and SRF shape raises the question of how side peak asymmetry emerges. Side peaks result from ITD computation by coincidence detector neurons in the brainstem (Carr and Konishi, 1990; Yin and Chan, 1990). Early in the ITD pathway, cells narrowly tuned to frequency respond to ITD ambiguously. This ambiguity is resolved in ICx where frequency bands converge. The main peak in the ITD tuning of ICx neurons corresponds to the characteristic delay of the neurons (Rose et al., 1967; Takahashi and Konishi, 1986). Responses at phase-equivalent ITDs are attenuated but not completely eliminated, thus forming side peaks (Takahashi and Konishi, 1986; Mazer, 1998; Peña and Konishi, 2000). It is possible for asymmetric side peaks to emerge through skewed alignment of ITD tuning across frequency (McAlpine et al., 1998). Alternatively, the space-dependent filtering properties of the owl's head and facial ruff (Payne, 1971; Knudsen and Konishi, 1979; Coles and Guppy, 1988) known as the head-related transfer function (HRTF) could contribute to SRF asymmetry. Because HRTFs show increased gain for sounds directly in front of the 
A

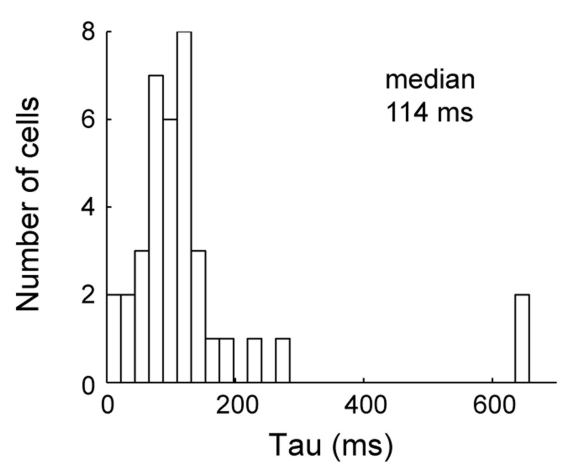

C

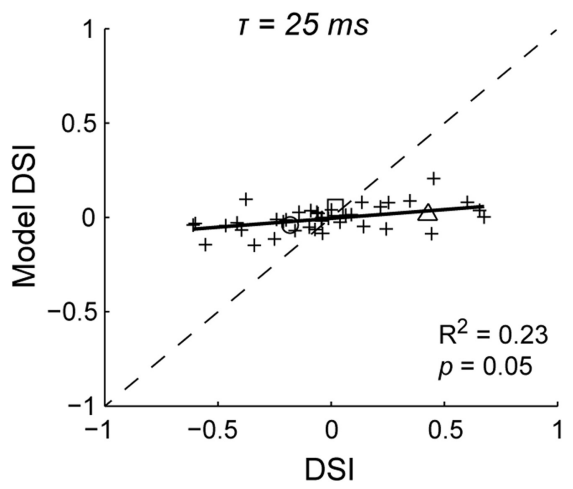

B

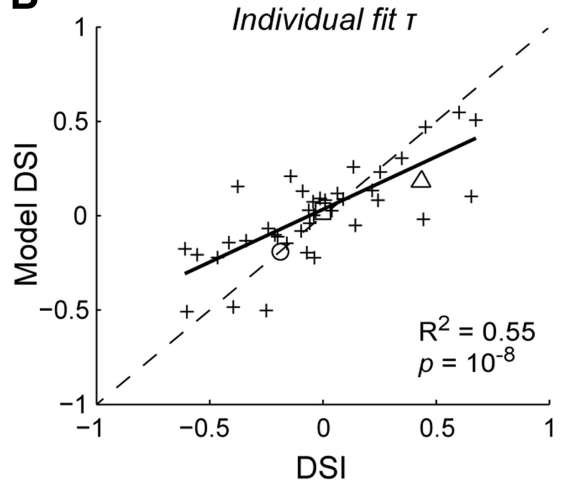

D

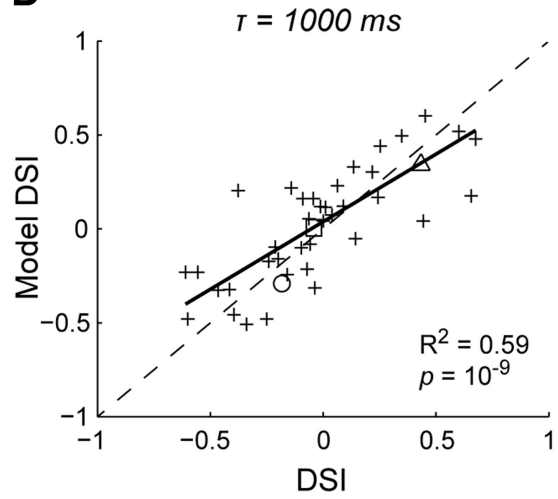

Figure 6. Dependence of direction selectivity on the adaptation time constant. $\boldsymbol{A}$, Distribution of adaptation time constants. $\boldsymbol{B}-\boldsymbol{D}$, DSI predictions using each cell's adaptation time constant $(\boldsymbol{B})$, short ( $25 \mathrm{~ms} ; \boldsymbol{C}$, and long (1000 ms) time constants (D). Short time constants underestimated direction selectivity. Predictions using longer time constants were similar to those made with each cell's $\tau$. Dashed lines and black lines represent the identity and regression lines between the model and data, respectively. Symbols $\bigcirc, \Delta$, and $\square$ indicate neurons shown in Figure $1 A-C$, respectively.

owl's face (Keller et al., 1998), side peaks closer to frontal space would be amplified by louder sound at the eardrums.

\section{Adaptation mechanism}

The adaptation reported here lasts several hundred milliseconds. We interpreted this time course as the lower limit for suppression decay rate to produce the observed DS, because very long $\tau$ also generated good predictions for DS. The observed adaptation time course is longer compared with in the auditory nerve (Harris and Dallos, 1979; Delgutte, 1990) and in the thalamus (Wehr and Zador, 2005) but similar to data using paired-stimulation in the IC (McAlpine et al., 2000; Ingham and McAlpine, 2004; Gutfreund and Knudsen, 2006; Singheiser et al., 2012), optic tectum (superior colliculus in mammals; Netser et al., 2011) and auditory cortex (Brosch and Schreiner, 1997; Wehr and Zador, 2005; Nelson et al., 2009; Lanting et al., 2013). Although these studies used similar paired-stimulation protocols and reported comparable recovery time scales, the phenomena studied may be either adaptation or forward suppression.

The commonly made distinction between forward suppression and adaptation is that forward suppression does not rely on the firing rate of the masker (Calford and Semple, 1995; Malone and Semple, 2001; Nelson et al., 2009), although this does not necessitate the mechanisms underlying these phenomena are mutually exclusive (Relkin and Turner, 1988; Oxenham, 2001). However, it is important to discern whether response suppression is dependent on the masker stimulus itself or on the response elicited by the masker (Sanes et al., 1998; Malone and Semple,
2001; Malone et al., 2002; Bartlett and Wang, 2005). Gutfreund and Knudsen (2006) showed the intensity of the masking stimulus in ICx is proportional to adaptation strength. Our data were consistent with this finding, as the difference in excitation at the side peaks predicted DS. However, we did not find a relationship between response history and adaptation strength on a trial-to-trial basis. This suggests adaptation may not rely on intrinsic spiking mechanisms (Priebe et al., 2002). It is possible that adaptation is relayed to ICx from upstream nuclei where similar properties have been observed (Singheiser et al., 2012). However, novel adaptation properties emerge within ICx, such as adaptation across frequency (Gutfreund and Knudsen, 2006).

Several mechanisms may mediate the long-lasting suppression (hundreds of milliseconds to seconds) observed in adaptation and forward suppression in the auditory system (Ulanovsky et al., 2004; Nelson et al., 2009). Although GABAergic inhibition plays a role in processing binaural cues (Fujita and Konishi, 1991; Sanes et al., 1998; Fukui et al., 2010), direction selectivity (Kautz and Wagner, 1998; Razak and Fuzessery, 2009) and stimulus-specific adaptation (Pérez-Gonzalez et al., 2012), modeling (Cai et al., 1998a,b), and intracellular recordings (Wehr and Zador, 2005) suggest the time course of inhibition is too short to account for the recovery time of adaptation. Further, spike-frequency adaptation (Ingham and McAlpine, 2004) and motion sensitivity in the IC (McAlpine and Palmer, 2002) are not eliminated by blocking GABAergic input. Alternatively, synaptic depression and afterhyperpolarization may contribute to the time course of adaptation.

\section{Validity of the model}

Our model assumes response adaptation sums linearly in time, resulting in direction selectivity if asymmetry is present. Linear summation of suppression is supported by psychophysics (Plack et al., 2006) and several studies on DS in vision (Enroth-Cugell et al., 1983; Jagadeesh et al., 1993, 1997). Similar to the relationship between DS and SRF asymmetries shown in the present study, the shape of spatiotemporal receptive fields in simple cells can predict the preferred motion direction (DeAngelis et al., 1993). Linear summation models can underestimate DS (Reid et al., 1991; DeAngelis et al., 1993; Oxenham, 2001) depending on the type of functions used to model the time-dependent suppression decay (Drew and Abbott, 2006).

\section{Effect of anesthesia}

In adequate dosages, ketamine anesthesia in birds does not cause profound changes in respiration and cardiovascular function (Degernes et al., 1988). Recovery time from response suppression obtained under ketamine-xylazine anesthesia is comparable with those obtained using other types of anesthesia, such as halothane and nitrous oxide (Gutfreund and Knudsen, 2006), ketamine and medetomidine (Wehr and Zador, 2005), and no anesthesia 
(Nelson et al., 2009). The administration of barbiturates can prolong recovery time from suppression (Wehr and Zador, 2005), whereas ketamine only mildly affects temporal properties in the IC (Ter-Mikaelian et al., 2007).

\section{Functional implications}

Direction selectivity can emerge by lateral connections within sensory maps. Adaptation, on the other hand, could give rise to direction selectivity in single cells. This mechanism could explain direction selectivity in auditory regions where space is not represented topographically (Rauschecker and Harris, 1989; Wilson and O'Neill, 1998; McAlpine et al., 2000; Ingham et al., 2001; Malone et al., 2002). Receptive fields in the visual (DeAngelis et al., 1995; Touryan et al., 2005) and auditory systems (Jenison et al., 2001) can take complex shapes. Thus, the asymmetry required for individual cells to become directional through adaptation may be a common feature in sensory systems.

\section{References}

Ahissar M, Ahissar E, Bergman H, Vaadia E (1992) Encoding of soundsource location and movement: activity of single neurons and interactions between adjacent neurons in the monkey auditory cortex. J Neurophysiol 67:203-215. Medline

Ayala YA, Malmierca MS (2013) Stimulus-specific adaptation and deviance detection in the inferior colliculus. Front Neural Circuits 6:89. CrossRef Medline

Bartlett EL, Wang X (2005) Long-lasting modulation by stimulus context in primate auditory cortex. J Neurophysiol 94:83-104. CrossRef Medline

Briggman KL, Helmstaedter M, Denk W (2011) Wiring specificity in the direction-selectivity circuit of the retina. Nature 471:183-188. CrossRef Medline

Brosch M, Schreiner CE (1997) Time course of forward masking tuning curves in cat primary auditory cortex. J Neurophysiol 77:923-943. Medline

Cai H, Carney LH, Colburn HS (1998a) A model for binaural response properties of inferior colliculus neurons: I. A model with interaural time difference-sensitive excitatory and inhibitory inputs. J Acoust Soc Am 103:475-493. CrossRef Medline

Cai H, Carney LH, Colburn HS (1998b) A model for binaural response properties of inferior colliculus neurons: II. A model with interaural time difference-sensitive excitatory and inhibitory inputs and an adaptation mechanism. J Acoust Soc Am 103:494-506. CrossRef Medline

Calford MB, Semple MN (1995) Monaural inhibition in cat auditory cortex. J Neurophysiol 73:1876-1891. Medline

Carr CE, Konishi M (1990) A circuit for detection of interaural time differences in the brain stem of the barn owl. J Neurosci 10:3227-3246. Medline

Casseday JH, Ehrlich D, Covey E (1994) Neural tuning for sound duration: role of inhibitory mechanisms in the inferior colliculus. Science 264:847850. CrossRef Medline

Coles RB, Guppy A (1988) Directional hearing in the barn owl (Tyto alba). J Comp Physiol A 163:117-133. CrossRef Medline

DeAngelis GC, Ohzawa I, Freeman RD (1993) Spatiotemporal organization of simple-cell receptive fields in the cat's striate cortex: II. Linearity of temporal and spatial summation. J Neurophysiol 69:1118-1135. Medline

DeAngelis GC, Ohzawa I, Freeman RD (1995) Receptive-field dynamics in the central visual pathways. Trends Neurosci 18:451-458. CrossRef Medline

Degernes LA, Kreeger TJ, Mandsager R, Redig PT (1988) Ketamine-xylazine anesthesia in red-tailed hawks with antagonism by yohimbine. J Wildl Dis 24:322-326. CrossRef Medline

Delgutte B (1990) Two-tone rate suppression in auditory-nerve fibers: dependence on suppressor frequency and level. Hear Res 49:225-246. CrossRef Medline

Drew PJ, Abbott LF (2006) Models and properties of power-law adaptation in neural systems. J Neurophysiol 96:826-833. CrossRef Medline

Enroth-Cugell C, Robson JG, Schweitzer-Tong DE, Watson AB (1983) Spatio-temporal interactions in cat retinal ganglion cells showing linear spatial summation. J Physiol 341:279-307. Medline

Fitzpatrick DC, Kuwada S, Batra R, Trahiotis C (1995) Neural responses to simple simulated echoes in the auditory brain stem of the unanesthetized rabbit. J Neurophysiol 74:2469-2486. Medline
Fujita I, Konishi M (1991) The role of GABAergic inhibition in processing of interaural time difference in the owl's auditory system. J Neurosci 11:722-739. Medline

Fukui I, Burger RM, Ohmori H, Rubel EW (2010) GABAergic inhibition sharpens the frequency tuning and enhances phase locking in chicken nucleus magnocellularis neurons. J Neurosci 30:12075-12083. CrossRef Medline

Getzmann S (2011) Auditory motion perception: onset position and motion direction are encoded in discrete processing stages. Eur J Neurosci 33:1339-1350. CrossRef Medline

Gutfreund Y, Knudsen EI (2006) Adaptation in the auditory space map of the barn owl. J Neurophysiol 96:813-825. CrossRef Medline

Harris DM, Dallos P (1979) Forward masking of auditory nerve fiber responses. J Neurophysiol 42:1083-1107. Medline

Ingham NJ, McAlpine D (2004) Spike-frequency adaptation in the inferior colliculus. J Neurophysiol 91:632-645. CrossRef Medline

Ingham NJ, Hart HC, McAlpine D (2001) Spatial receptive fields of inferior colliculus neurons to auditory apparent motion in free field. J Neurophysiol 85:23-33. Medline

Jagadeesh B, Wheat HS, Ferster D (1993) Linearity of summation of synaptic potentials underlying direction selectivity in simple cells of the cat visual cortex. Science 262:1901-1904. CrossRef Medline

Jagadeesh B, Wheat HS, Kontsevich LL, Tyler CW, Ferster D (1997) Direction selectivity of synaptic potentials in simple cells of the cat visual cortex. J Neurophysiol 78:2772-2789. Medline

Jenison RL, Schnupp JW, Reale RA, Brugge JF (2001) Auditory space-time receptive field dynamics revealed by spherical white-noise analysis. J Neurosci 21:4408-4415. Medline

Kautz D, Wagner H (1998) GABAergic inhibition influences auditory motion-direction sensitivity in barn owls. J Neurophysiol 80:172-185. Medline

Keller CH, Hartung K, Takahashi TT (1998) Head-related transfer functions of the barn owl: measurement and neural responses. Hear Res 118: 13-34. CrossRef Medline

Knudsen EI, Konishi M (1978) A neural map of auditory space in the owl. Science 200:795-797. CrossRef Medline

Knudsen EI, Konishi M (1979) Mechanisms of sound localization in the barn owl (Tyto alba). J Comp Physiol A 133:13-21. CrossRef

Kuo RI, Wu GK (2012) The generation of direction selectivity in the auditory system. Neuron 73:1016-1027. CrossRef Medline

Lanting CP, Briley PM, Sumner CJ, Krumbholz K (2013) Mechanisms of adaptation in human auditory cortex. J Neurophysiol 110:973-983. CrossRef Medline

Malone BJ, Semple MN (2001) Effects of auditory stimulus context on the representation of frequency in the gerbil inferior colliculus. J Neurophysiol 86:1113-1130. Medline

Malone BJ, Scott BH, Semple MN (2002) Context-dependent adaptive coding of interaural phase disparity in the auditory cortex of awake macaques. J Neurosci 22:4625-4638. Medline

Mazer JA (1998) How the owl resolves auditory coding ambiguity. Proc Natl Acad Sci U S A 95:10932-10937. CrossRef Medline

McAlpine D, Palmer AR (2002) Blocking GABAergic inhibition increases sensitivity to sound motion cues in the inferior colliculus. J Neurosci 22:1443-1453. Medline

McAlpine D, Jiang D, Shackleton TM, Palmer AR (1998) Convergent input from brainstem coincidence detectors onto delay-sensitive neurons in the inferior colliculus. J Neurosci 18:6026-6039. Medline

McAlpine D, Jiang D, Shackleton TM, Palmer AR (2000) Responses of neurons in the inferior colliculus to dynamic interaural phase cues: evidence for a mechanism of binaural adaptation. J Neurophysiol 83:1356-1365. Medline

Mendelson JR, Cynader MS (1985) Sensitivity of cat primary auditorycortex $(\mathrm{Al})$ neurons to the direction and rate of frequency-modulation. Brain Res 327:331-335. CrossRef Medline

Moiseff A, Konishi M (1981) Neuronal and behavioral sensitivity to binaural time differences in the owl. J Neurosci 1:40-48. Medline

Moiseff A, Konishi M (1983) Binaural characteristics of units in the owl's brainstem auditory pathway: precursors of restricted spatial receptive fields. J Neurosci 3:2553-2562. Medline

Mori K (1997) Across-frequency nonlinear inhibition by GABA in processing of interaural time difference. Hear Res 111:22-30. CrossRef Medline

Nelson PC, Smith ZM, Young ED (2009) Wide-dynamic-range forward suppression in marmoset inferior colliculus neurons is generated cen- 
trally and accounts for perceptual masking. J Neurosci 29:2553-2562. CrossRef Medline

Netser S, Zahar Y, Gutfreund Y (2011) Stimulus-specific adaptation: can it be a neural correlate of behavioral habituation? J Neurosci 31:1781117820. CrossRef Medline

Oxenham AJ (2001) Forward masking: adaptation or integration? J Acoust Soc Am 109:732-741. CrossRef Medline

Payne RS (1971) Acoustic location of prey by barn owls (Tyto alba). J Exp Biol 54:535-573. Medline

Peña JL, Konishi M (2000) Cellular mechanisms for resolving phase ambiguity in the owl's inferior colliculus. Proc Natl Acad Sci U S A 97:1178711792. CrossRef Medline

Peña JL, Konishi M (2001) Auditory spatial receptive fields created by multiplication. Science 292:249-252. CrossRef Medline

Pérez ML, Peña JL (2006) Comparison of midbrain and thalamic spacespecific neurons in barn owls. J Neurophysiol 95:783-790. CrossRef Medline

Pérez-Gonzalez D, Hernández O, Covey E, Malmierca MS (2012) GABA(A)-mediated inhibition modulates stimulus-specific adaptation in the inferior colliculus. PLoS One 7:e34297. CrossRef Medline

Plack CJ, Oxenham AJ, Drga V (2006) Masking by inaudible sounds and the linearity of temporal summation. J Neurosci 26:8767-8773. CrossRef Medline

Priebe NJ, Churchland MM, Lisberger SG (2002) Constraints on the source of short-term motion adaptation in macaque area MT: I. The role of input and intrinsic mechanisms. J Neurophysiol 88:354-369. Medline

Quiroga RQ, Nadasdy Z, Ben-Shaul Y (2004) Unsupervised spike detection and sorting with wavelets and superparamagnetic clustering. Neural Comput 16:1661-1687. CrossRef Medline

Rauschecker JP (1997) Processing of complex sounds in the auditory cortex of cat, monkey, and man. Acta Otolaryngol Suppl 532:34-38. Medline

Rauschecker JP, Harris LR (1989) Auditory and visual neurons in the cat's superior colliculus selective for the direction of apparent motion stimuli. Brain Res 490:56-63. CrossRef Medline

Razak KA, Fuzessery ZM (2006) Neural mechanisms underlying selectivity for the rate and direction of frequency-modulated sweeps in the auditory cortex of the pallid bat. J Neurophysiol 96:1303-1319. CrossRef Medline

Razak KA, Fuzessery ZM (2009) GABA shapes selectivity for the rate and direction of frequency-modulated sweeps in the auditory cortex. J Neurophysiol 102:1366-1378. CrossRef Medline

Reale RA, Brugge JF (1990) Auditory cortical neurons are sensitive to static and continuously changing interaural phase cues. J Neurophysiol 64: 1247-1260. Medline

Reid RC, Soodak RE, Shapley RM (1991) Directional selectivity and spatiotemporal structure of receptive fields of simple cells in cat striate cortex. J Neurophysiol 66:505-529. Medline

Relkin EM, Turner CW (1988) A reexamination of forward masking in the auditory nerve. J Acoust Soc Am 84:584-591. CrossRef Medline

Rose JE, Brugge JF, Anderson DJ, Hind JE (1967) Phase-locked response to low-frequency tones in single auditory nerve fibers of the squirrel monkey. J Neurophysiol 30:769-793. Medline

Sanes DH, Malone BJ, Semple MN (1998) Role of synaptic inhibition in processing of dynamic binaural level stimuli. J Neurosci 18:794-803. Medline

Sen K, Jorge-Rivera JC, Marder E, Abbott LF (1996) Decoding synapses. J Neurosci 16:6307-6318. Medline

Shestopalova LB, Petropavlovskaia EA, Vaitulevich SP, Vasilenko YA, Nikitin NI, Altman JA (2012) Discrimination of auditory motion patterns: the mismatch negativity study. Neuropsychologia 50:2720-2729. CrossRef Medline

Singheiser M, Ferger R, von Campenhausen M, Wagner H (2012) Adaptation in the auditory midbrain of the barn owl (Tyto alba) induced by tonal double stimulation. Eur J Neurosci 35:445-456. CrossRef Medline

Sovijärvi AR, Hyvärinen J (1974) Auditory cortical neurons in the cat sensitive to the direction of sound source movement. Brain Res 73:455-471. CrossRef Medline

Spitzer MW, Semple MN (1993) Responses of inferior colliculus neurons to time-varying interaural phase disparity: effects of shifting the locus of virtual motion. J Neurophysiol 69:1245-1263. Medline

Steinberg LJ, Peña JL (2011) Difference in response reliability predicted by spectrotemporal tuning in the cochlear nuclei of barn owls. J Neurosci 31:3234-3242. CrossRef Medline

Stumpf E, Toronchuk JM, Cynader MS (1992) Neurons in cat primary auditory cortex sensitive to correlates of auditory motion in threedimensional space. Exp Brain Res 88:158-168. CrossRef Medline

Suga N, Schlegel P (1973) Coding and processing in the auditory systems of FM signal producing bats. J Acoust Soc Am 54:174-190. CrossRef Medline

Takahashi T, Konishi M (1986) Selectivity for interaural time difference in the owl's midbrain. J Neurosci 6:3413-3422. Medline

Takahashi T, Moiseff A, Konishi M (1984) Time and intensity cues are processed independently in the auditory system of the owl. J Neurosci 4:1781-1786. Medline

Ter-Mikaelian M, Sanes DH, Semple MN (2007) Transformation of temporal properties between auditory midbrain and cortex in the awake Mongolian gerbil. J Neurosci 27:6091-6102. CrossRef Medline

Tolhurst DJ, Heeger DJ (1997) Contrast normalization and a linear model for the directional selectivity of simple cells in cat striate cortex. Vis Neurosci 14:19-25. CrossRef Medline

Touryan J, Felsen G, Dan Y (2005) Spatial structure of complex cell receptive fields measured with natural images. Neuron 45:781-791. CrossRef Medline

Ulanovsky N, Las L, Farkas D, Nelken I (2004) Multiple time scales of adaptation in auditory cortex neurons. J Neurosci 24:10440-10453. CrossRef Medline

Vaney DI, Sivyer B, Taylor WR (2012) Direction selectivity in the retina: symmetry and asymmetry in structure and function. Nat Rev Neurosci 13:194-208. CrossRef Medline

Varela JA, Sen K, Gibson J, Fost J, Abbott LF, Nelson SB (1997) A quantitative description of short-term plasticity at excitatory synapses in layer $2 / 3$ of rat primary visual cortex. J Neurosci 17:7926-7940. Medline

Wagner H, Takahashi T (1990) Neurons in the midbrain of the barn owl are sensitive to the direction of apparent acoustic motion. Naturwissenschaften 77:439-442. CrossRef Medline

Wagner H, Takahashi T (1992) Influence of temporal cues on acoustic motion-direction sensitivity of auditory neurons in the owl. J Neurophysiol 68:2063-2076. Medline

Wagner H, von Campenhausen M (2002) Distribution of auditory motion-direction sensitive neurons in the barn owl's midbrain. J Comp Physiol A Neuroethol Sens Neural Behav Physiol 188:705-713. CrossRef Medline

Wagner H, Asadollahi A, Bremen P, Endler F, Vonderschen K, von Campenhausen M (2007) Distribution of interaural time difference in the barn owl's inferior colliculus in the low- and high-frequency ranges. J Neurosci 27:4191-4200. CrossRef Medline

Wang Y, Shanbhag SJ, Fischer BJ, Peña JL (2012) Population-wide bias of surround suppression in auditory spatial receptive fields of the owl's midbrain. J Neurosci 32:10470-10478. CrossRef Medline

Wehr M, Zador AM (2005) Synaptic mechanisms of forward suppression in rat auditory cortex. Neuron 47:437-445. CrossRef Medline

Wei W, Hamby AM, Zhou K, Feller MB (2011) Development of asymmetric inhibition underlying direction selectivity in the retina. Nature 469:402406. CrossRef Medline

Wilson WW, O'Neill WE (1998) Auditory motion induces directionally dependent receptive field shifts in inferior colliculus neurons. J Neurophysiol 79:2040-2062. Medline

Ye CQ, Poo MM, Dan Y, Zhang XH (2010) Synaptic mechanisms of direction selectivity in primary auditory cortex. J Neurosci 30:1861-1868. CrossRef Medline

Yin TC (1994) Physiological correlates of the precedence effect and summing localization in the inferior colliculus of the cat. J Neurosci 14:5170-5186. Medline

Yin TC, Chan JC (1990) Interaural time sensitivity in medial superior olive of cat. J Neurophysiol 64:465-488. Medline

Zhang LI, Tan AY, Schreiner CE, Merzenich MM (2003) Topography and synaptic shaping of direction selectivity in primary auditory cortex. Nature 424:201-205. CrossRef Medline

Zhou B, Green DM, Middlebrooks JC (1992) Characterization of external ear impulse responses using Golay codes. J Acoust Soc Am 92:1169-1171. CrossRef Medline 